\title{
High time resolution PFISR and optical observations of naturally enhanced ion acoustic lines
}

\author{
R. G. Michell ${ }^{1, *}$, K. A. Lynch $^{1}$, C. J. Heinselman ${ }^{2}$, and H. C. Stenbaek-Nielsen ${ }^{3}$ \\ ${ }^{1}$ Dartmouth College, Department of Physics and Astronomy, Hanover, NH, USA \\ ${ }^{2}$ SRI, International, Menlo Park, CA, USA \\ ${ }^{3}$ University of Alaska, Fairbanks, Geophysical Institute, Fairbanks, AK, USA \\ * currently at: Southwest Research Institute, San Antonio, TX, USA
}

Received: 6 December 2007 - Revised: 18 February 2009 - Accepted: 2 March 2009 - Published: 1 April 2009

\begin{abstract}
Observations of naturally enhanced ion acoustic lines (NEIALs) taken with the Poker Flat Incoherent Scatter Radar (PFISR) using a mode with very high time resolution are presented. The auroral event took place over Poker Flat, Alaska on 8 February 2007 at 09:35 UT ( 22:00 MLT), and the radar data are complemented by common-volume highresolution auroral imaging. The NEIALs occurred during only one of the standard 15-s integration periods. The raw data of this time show very intermittent NEIALs which occur only during a few very short time intervals $(\leq 1 \mathrm{~s})$ within the 15 -s period. The time sampling of the raw data, $\sim 19 \mathrm{~ms}$ on average, allows study of the time development of the NEIALs, though there are indications that even finer time resolution would be of interest. The analysis is based on the assumption that the NEIAL returns are the result of Bragg scattering from ion-acoustic waves that have been enhanced significantly above thermal levels. The spectra of the raw data indicate that although the up- and down-shifted shoulders can both become enhanced at the same time, (within $19 \mathrm{~ms}$ ), they are most often enhanced individually. The overall power in the up-and down-shifted shoulders is approximately equal throughout the event, with the exception of one time, when very large up-shifted power was observed with no corresponding down-shifted power. This indicates that during the $480 \mu$ s pulse, the strongly enhanced ion-acoustic waves were only traveling downward and not upward. The exact time that the NEIALs occurred was when the radar beam was on the boundary of a fast-moving $(\sim 10 \mathrm{~km} / \mathrm{s})$, bright auroral structure, as seen in the high resolution auroral imaging of the magnetic zenith. When viewed with high
\end{abstract}

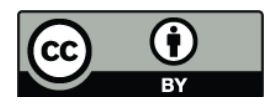

Correspondence to: R. G. Michell (rmichell@swri.edu) time resolution, the occurrence of NEIALs is associated with rapid changes in auroral luminosity within the radar field of view due to fast-moving auroral fine structures.

Keywords. Ionosphere (Plasma waves and instabilities; Wave-particle interactions) - Magnetospheric physics (Auroral phenomena)

\section{Introduction}

The origin of naturally enhanced ion acoustic lines (NEIALs) in incoherent scatter radar (ISR) data has long been a mystery. Their observation in ISR data is well documented (Foster et al., 1988; Rietveld et al., 1991; Collis et al., 1991; Sedgemore-Schulthess et al., 1999; Ogawa et al., 2000; Grydeland et al., 2003, 2004; Strømme et al., 2005; Blixt et al., 2005; Ogawa et al., 2006; Lunde et al., 2007), and many theories exist to explain their generation (Foster et al., 1988; Rietveld et al., 1991; Wahlund et al., 1992; Forme, 1993, 1999; Strømme et al., 2005). The three main theories involve the electron-ion two-stream (current-driven) instability, the ion-ion two-stream instability, and non-linear wavewave interactions (Langmuir decay) (Sedgemore-Schulthess and St. Maurice, 2001). However, the observational data reported so far are insufficient to test the validity of these different theories. Simultaneous and non-simultaneous observations of enhancements in both up- and down-shifted ionacoustic shoulders have differing implications for the generation mechanisms of NEIALs.

ISR measurements are typically integrated into several second intervals in order to decrease the uncertainties associated with small-number counting statistics, which is necessary to extract meaningful results. It is therefore these

Published by Copernicus Publications on behalf of the European Geosciences Union. 
integrated data that are typically saved and used for analyses. Previous studies of NEIALs, with the exception of Grydeland et al. (2003, 2004), have used such integrated data. However, it was noted by Grydeland et al. $(2003,2004)$ that the occurrence of NEIALs can show significant variation between adjacent five- or ten-second integration periods, and therefore the processes involved must be occurring on shorter timescales. It was demonstrated by Grydeland et al. (2003) that the enhanced returns were coming from a small region of space (a few hundred meters perpendicular to the magnetic field) and occurring for very short times (sub-second), indicating that the returns were several orders of magnitude stronger than ordinary ISR returns and, therefore, could be detected with much shorter integration times. Grydeland et al. $(2003,2004)$ examined NEIAL events with high time resolution by integrating the raw data into $200 \mathrm{~ms}$ periods. They found that both the up- and down-shifted lines occurred simultaneously within the $200 \mathrm{~ms}$ integration periods, also noting that even with 50 to $100 \mathrm{~ms}$ integrations the overall development of the event was unchanged. Grydeland et al. $(2003,2004)$ also used interferometry to localize the region containing the NEIALs to within $\sim 300 \mathrm{~m}$ perpendicular to the magnetic field at $500 \mathrm{~km}$ altitude.

The question remains as to whether there is still temporal averaging occurring on timescales below $50 \mathrm{~ms}$. Examining the raw voltage samples in combination with the auroral images, as done below, can give an indication of the relevant time scales for conditional integration of the raw data. The rapid changes in auroral luminosity give an indication of the intervals where the assumption of time stationary plasma may not hold.

It is the purpose of this paper to investigate the temporal evolution of NEIALs at a high time resolution, $19 \mathrm{~ms}$ in this case, to gain insight into the time scales associated with their development and relationship to auroral fine structures. The auroral context in which they occur is also examined, and suggests a connection on the nightside between NEIALs and auroral boundary regions. One of the main goals of studying the raw data NEIAL returns is to gain insight into their generation mechanisms.

\section{Observations}

\subsection{Integrated data}

The auroral event examined here took place over Poker Flat, Alaska $\left(65.12^{\circ} \mathrm{N}, 212.56^{\circ} \mathrm{E}\right.$, (geographic)) on 8 February 2007 at 09:35 UT, approximately $2 \mathrm{~h}$ before magnetic midnight. The Poker Flat Incoherent Scatter Radar (PFISR), which is based on Advanced Modular Incoherent Scatter Radar (AMISR) technology, was operating in a mode that recorded both the integrated and the raw data from the longpulse $(480 \mu \mathrm{s})$ measurements, at $449 \mathrm{MHz}$. These data are from the magnetic field-aligned beam $\left(205.7^{\circ} \mathrm{Az} ., 77.5^{\circ} \mathrm{El}\right.$. $)$ and the beam width is approximately $1^{\circ} \times 1^{\circ}$. These long uncoded pulses allow the spectral information of the returns to be examined. The integrated data have a time resolution of $15 \mathrm{~s}$, but with this mode the raw data from the field-aligned beam have a time resolution of $\sim 19 \mathrm{~ms}$ on average. The cameras used in this study included a narrow field $\left(12^{\circ}\right.$ by $16^{\circ}$ ) imager equipped with a filter to remove the $557.7 \mathrm{~nm}$ emission, and an all-sky imager (unfiltered), both located at Poker Flat. Both cameras are image-intensified CCD cameras recording to DVD at 30 frames per second. The filter on the narrow field camera was a Kodak \# 32 Wratten filter, a notch filter, to remove $557.7 \mathrm{~nm}$ preventing the fixed-gain imager from becoming saturated by these intense emissions. The narrow field imager is centered on the direction of the local magnetic zenith $\left(210.0^{\circ}\right.$ Az., $77.0^{\circ}$ El.), so the radar beam location is well within the field of view (FOV) of the imager.

Figure 1a shows the electron density estimate (scaled received power, assuming $T_{e}=T_{i}$ ) from the integrated radar data. Shortly after 09:34 UT (9.58 on Fig. 1) there is one interval with very enhanced returns in the F-region. These data are from the nighttime, winter ionosphere and therefore there is essentially no F-region. There is, however, a slightly enhanced E-region caused by diffuse auroral precipitation. Near the end of this time interval, the E-region becomes much more enhanced and extended both up and down in altitude. This is caused by active auroral structures which moved into the zenith from the north, which were seen in the all-sky camera data. This active aurora contained a larger electron energy flux than the diffuse auroral precipitation preceding this time. This is indicated by the enhanced electron density extending both to lower and higher altitudes. The NEIAL returns occur as the edge of this auroral activity passes through the magnetic zenith. Figure $1 \mathrm{~b}$ shows the spectra taken from the same integrated data, averaged over the range of altitudes (200 to $350 \mathrm{~km}$ ) where the enhanced returns occur. After the NEIAL, the 2 ion-acoustic shoulders become more distinct, due to the enhanced precipitating electron flux, which caused increases in both electron density and temperature. Figure 1c shows a line cut of the spectra from Fig. 1b, from the time period of the enhancement, and, for comparison, the dotted line shows the spectra from the time period just prior to the enhancement. Most of the enhanced returns at 09.58 UT occur at the ion-acoustic shoulders $( \pm 4 \mathrm{kHz}$ in this case), though the returns are somewhat enhanced throughout the frequency band between the two ion-acoustic shoulders.

Figure 2 shows the returned power as a function of frequency and altitude for three consecutive 15-s integration periods. Figure 2a shows the period before the NEIALs, Fig. $2 \mathrm{~b}$ shows the period containing the NEIALs, and Fig. $2 \mathrm{c}$ shows the period after the NEIALs. All three are plotted on the same intensity scale. It can be seen that the time of the NEIALs contains significantly more enhanced returns over this altitude range, and also that both the upshifted and downshifted shoulders are enhanced by approximately the same 
(a) $20070208 \mathrm{e}^{-}$density $\left(\mathrm{m}^{-3}\right) \quad \mathrm{A} z=-154.3, \mathrm{El}=77.5$

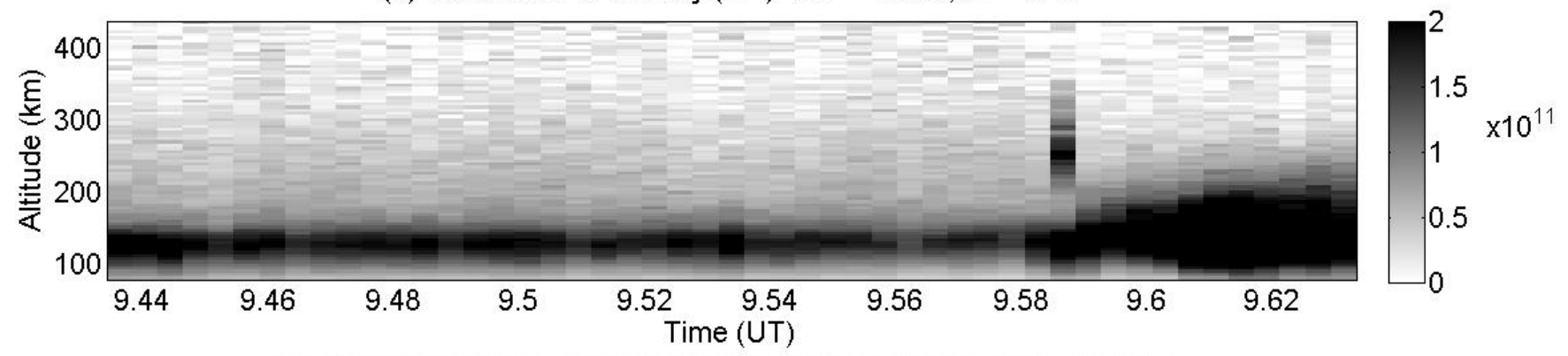

(b) 20070208 Power Spectral Density (Altitude Range $=200-350 \mathrm{~km}$ )

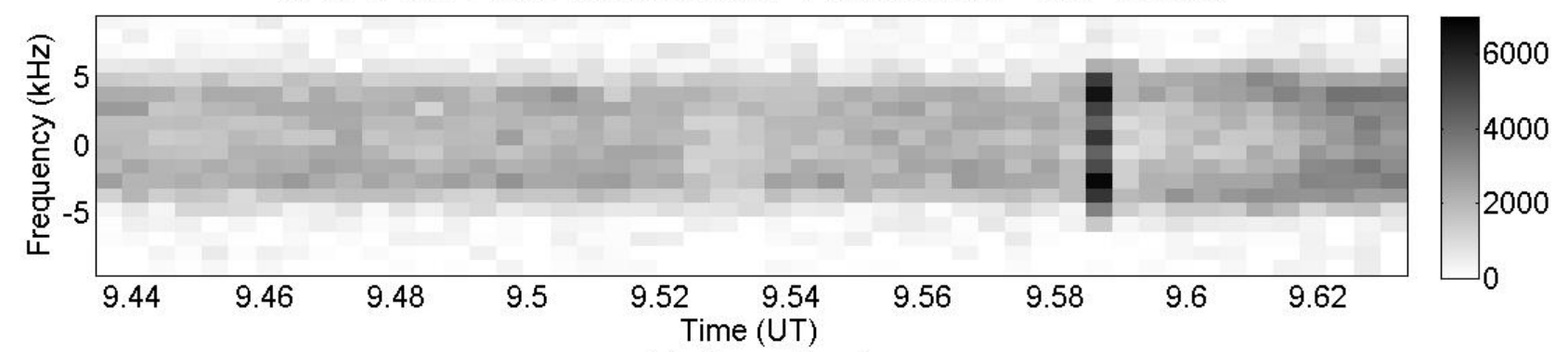

(c) Power Spectrum

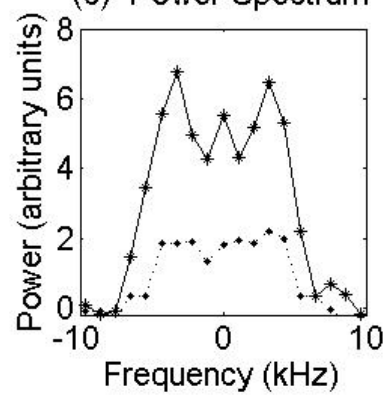

Fig. 1. Panel (a) shows the electron density in $\left(\mathrm{m}^{-3}\right)$ as a function of altitude and time, showing the abnormally large returns near $9.58 \mathrm{UT}$. (b) The returned power as a function of frequency and time, averaged over 200 to $350 \mathrm{~km}$ altitude. (c) Spectra for the period of the enhancement. The dotted line shows the spectra from the time period before the enhancement. These are all calculated from the integrated data. The integration containing the enhancement covers 09:34:57 to 09:35:12 UT.

amount, indicating that on this timescale $(15 \mathrm{~s})$ there is no overall asymmetry in the power of the returns. The NEIALs are also seen to occur over a fairly narrow altitude range $(200$ to $350 \mathrm{~km}$ on average).

\subsection{Raw data}

The raw data of this 15 -s period (09:34:57 to $09: 35: 12$ UT) were examined and it was found that the strong returns occur only during a $5 \mathrm{~s}$ period from 09:35:05 to 09:35:10 UT. Furthermore, these returns come only from very short times within this 5-s period. Figure 3 shows a summary of the returned power from the un-integrated raw data for this 5 -s period. The raw data have not been corrected for the $\frac{1}{r^{2}}$ decrease in power with range, and therefore the actual intensity of these returns is significantly higher than those at $100 \mathrm{~km}$ altitude. The line overplotted on the data is the average in- tensity per pixel of the aurora inside the radar beam as seen by the narrow field camera. The camera data have a time resolution of $33 \mathrm{~ms}$.

The apparent high range resolution is due to the sampling frequency $(30 \mu \mathrm{s})$. The meaningful altitude resolution of this data, from $480 \mu \mathrm{s}$ pulses, is $72 \mathrm{~km}$. Although the returns appear to be very localized in altitude, due to the statistical nature of the scattering, they are very localized in time, occurring only during short time intervals within the $480 \mu$ s pulse. These data show that the returned power is very structured in time and very localized in space, given the high time resolution optical auroral observations.

An important point to be made regarding the use of raw incoherent scatter data is that each pulse represents a single sample of a random process and therefore can only be interpreted by integrating multiple pulses together. The only 

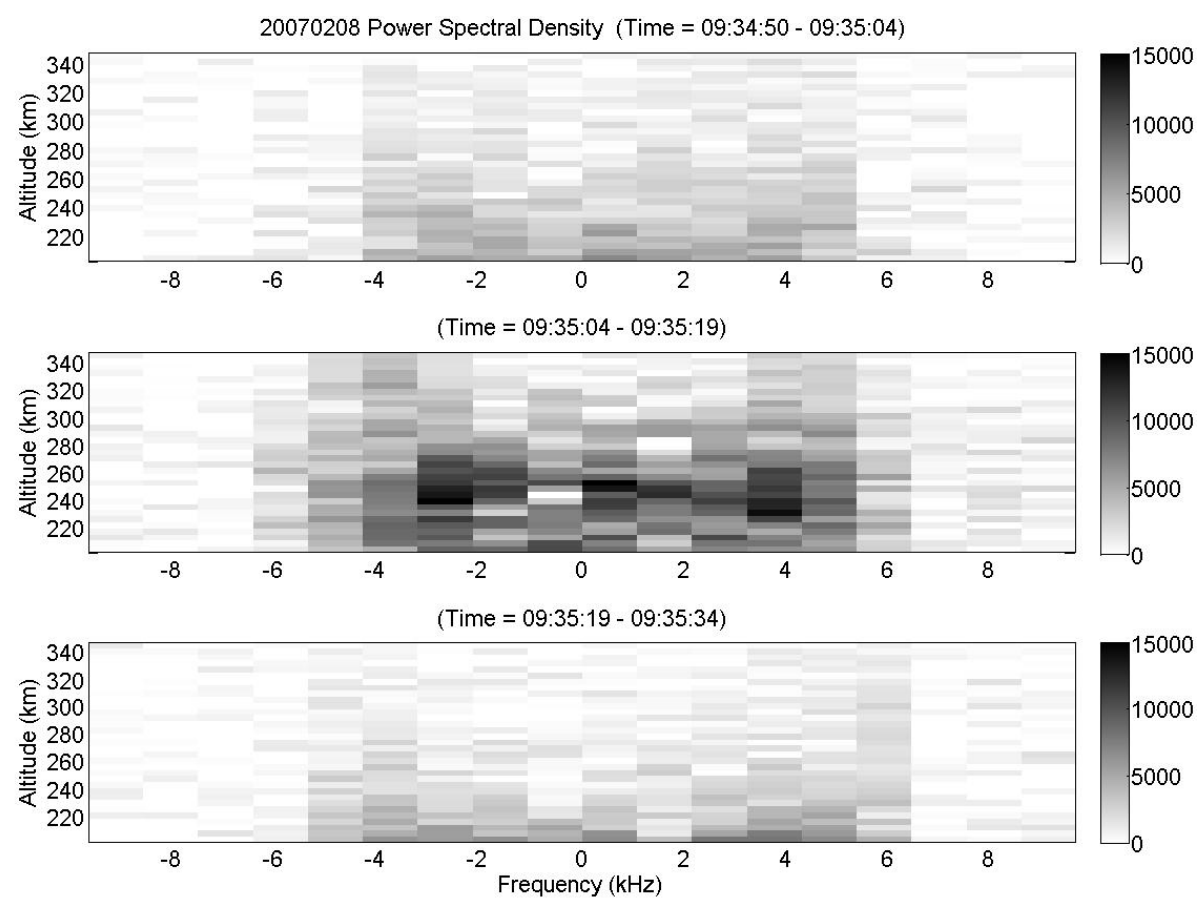

Fig. 2. The returned power as a function of altitude and frequency for 3 consecutive times, plotted with the same scale. (a) shows the time immediately before the NEIAL, (b) shows the time containing the NEIAL and (c) shows the time immediately after the NEIAL. These are also taken from the integrated data with $15 \mathrm{~s}$ time resolution.

meaningful use of unprocessed raw backscattered power is during cases of coherent scattering, as in the case of meteor and hard target (satellite) echoes. We argue that NEIALs appear to exhibit characteristics of coherent backscatter in the localization and strength of the returned echo. There have been many techniques developed to process raw ISR data allowing the extraction of useful parameters (Markkanen et al., 2005; Grydeland et al., 2008). Future raw data NEIAL observations will employ the use of such raw data processing schemes, likely aided by high resolution auroral imaging.

The exact nature of the scattering processes within the NEIALs are not known, and neither are the physical processes generating the NEIAL structures. Therefore, the subsequent analysis assumes that NEIALs result from coherency in the plasma, on the Bragg scattering scale, likely resulting from enhanced wave activity. The signal will be examined at the pulse-to-pulse level and the occurrence of NEIALs in the raw data can be closely correlated in time with the presence of auroral structures within the radar beam.

\subsection{Camera data}

The auroral luminosity lineplot, overlaid on Fig. 3, shows that the NEIALs occur within the boundaries of the bright auroral structures. This line spans the intensity range from 23 to 44 on a scale of 0 to 255 . Therefore the increase in luminosity is a factor of 2 between the brightest and dark- est regions of the line plot. The E-region returns are very stochastic because they are from the unintegrated, raw incoherent scatter data. On this timescale, there is no enhancement in the E-region visible corresponding with the peak in the light curve because the raw incoherent scatter data have a signal to signal-variance ratio far too low to distinguish it, even though the actual electron density would increase there. On longer timescales, for example, using the 15-s integrated data, the E-region density correlates very well with the auroral luminosity within the radar field of view as showed in Fig. 2 of Michell et al. (2008a).

Figure 4 shows a series of images taken from the imager during the seconds corresponding to the times of Fig. 3 . The numbers given in the upper left corner of each image, namely, :05,:06,:07,:08,:09, and :10, correspond to the time of each image in seconds after 09:35:00 UT. The white box denotes the location of the radar beam at $100 \mathrm{~km}$ altitude. The images and radar beam location are mapped to geodetic coordinates, with an assumed altitude of $100 \mathrm{~km}$ for the auroral emissions. In these mapped images, magnetic north is at the top and east is to the right (i.e., view from above). It can be seen from Fig. 4 that a dynamic, small-scale, rayed arc passes through the radar beam between :09 and :10, but Fig. 3 shows that the strongest NEIAL returns occur between around :06 and :07, when the radar beam is on the boundary of the bright arc. Figure 3 also shows that the NEIAL 


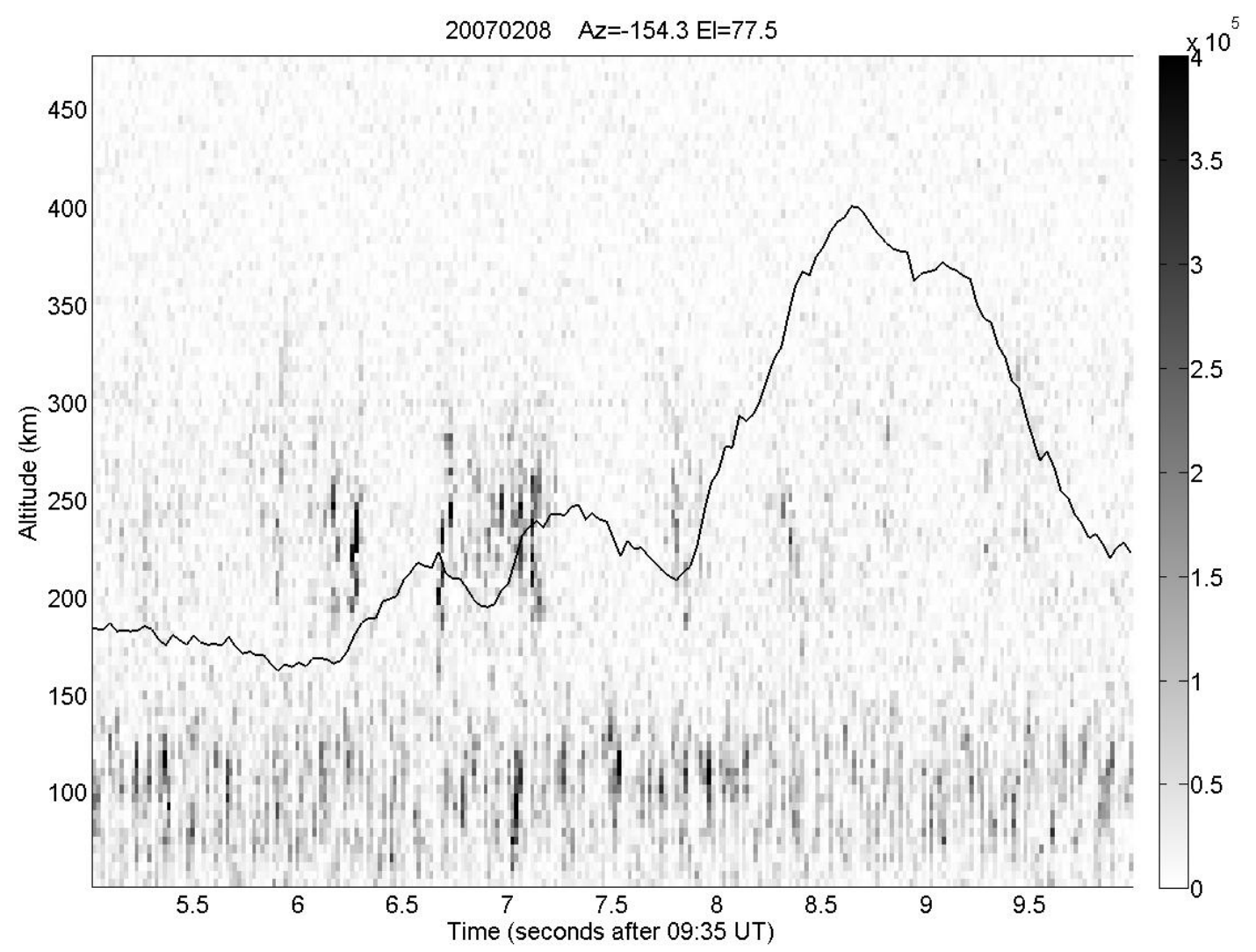

Fig. 3. The returned power from the raw data, in arbitrary units, $(\sim 19 \mathrm{~ms}$ resolution $)$, showing that the large returns are coming from very short time intervals within the $15 \mathrm{~s}$ integration period of the integrated data. The line overplotted shows the relative intensity of the aurora from the region inside the radar beam, taken from the camera data $\left(\sim 33 \mathrm{~ms}\right.$ resolution). The raw power is not corrected for the $\frac{1}{r^{2}}$ decrease in power with distance. The returns near $100 \mathrm{~km}$ altitude are the signal from the incoherent scatter associated with the E-region plasma.

occurrence follows some of the smaller-scale variations in the luminosity. There are also some less intense enhanced returns throughout the region between 8.0 and $9.5 \mathrm{~s}$ (centered on the arc). These could be associated with even smallerscale precipitation filaments inside the region of brighter aurora, which would not be resolvable with this imager. The real-time auroral movies of this event show that this small, dynamic auroral structure was rapidly moving south (few $\mathrm{km} / \mathrm{s}$ ), and composed of counter-clockwise curling features. Therefore the changes in auroral luminosity are due to motions of structures into and out of the field of view and not time varying spatial structures. Some of the background luminosity is associated with an unstructured aurora that precedes the active aurora.

This auroral event took place $2 \mathrm{~h}$ prior to magnetic midnight, during the onset of the expansion phase of an auroral activation. Figure 5 shows an all-sky camera image from the time when the NEIALs were observed (09:35:06 UT). The small black box near the center of the image denotes the location of the radar beam, which is in the magnetic zenith. In this figure, magnetic north is at the bottom and east is to the right (view from below). It can be seen that there were tall dynamic auroral rays present throughout most of the northern half of the sky, and the NEIALs were observed in a dark region on the southern (equatorward) edge of this activity. The active aurora seen in the north of Fig. 5 did not move significantly farther south, and therefore did not come into the magnetic zenith. There were 6 other radar beams operating, which were pointed mostly to the north. These are all oblique to the magnetic field by $\geq 30^{\circ}$, and the data from these beams showed no indication of enhanced returns. This is consistent with previous studies indicating that NEIAL observation is typically sensitive to aspect angle, with the strongest returns being observed more field aligned (Collis et al., 1991; Rietveld et al., 1996).

\subsection{Frequency component of NEIALs}

We return now to the discussion regarding the raw power returns shown in Fig. 3. Figure 6 shows again the returned power of the NEIALs at $19 \mathrm{~ms}$ resolution, as in Fig. 3, but showing also here the frequency of the enhanced returns as a function of altitude and time. These data are also not 


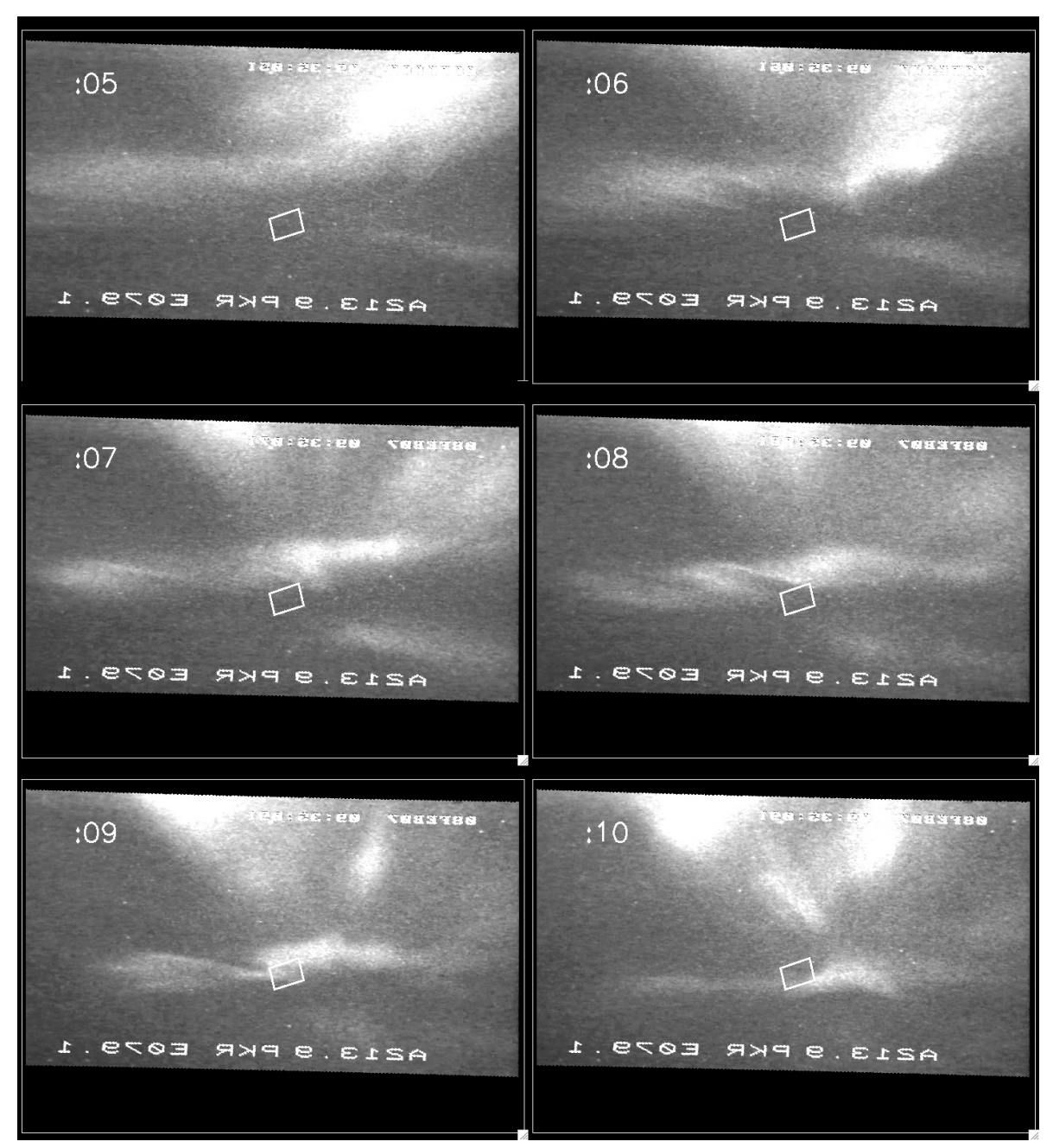

Fig. 4. Series of mapped camera images taken on every second corresponding to the times in Fig. 3. This shows the active dynamic auroral arc passing through the radar beam, denoted by the white box. An altitude of $100 \mathrm{~km}$ is assumed for the location of the aurora and the radar beam location. The time in seconds from 09:35 UT is shown in the upper left corner of each image. (In magnetic coordinates, north is up and east is to the right).

corrected for the $\frac{1}{r^{2}}$ decrease in power with altitude, and the power is expressed in normalized units. These returns are broken down into two frequency ranges: up-shifted shoulders $(2$ to $7 \mathrm{kHz})$ shown in blue, and down-shifted shoulders $(-7$ to $-2 \mathrm{kHz})$ shown in red. Upshifted power is indicative of ion-acoustic waves traveling toward the radar, while downshifted power comes from waves traveling away from the radar. From Fig. 6 it can be seen that there are some regions where there is overlap between the enhanced up- and down-shifted lines. However, with this resolution $(\sim 19 \mathrm{~ms})$, it appears that most of the time, the up- and the down-shifted lines are occurring independently of one another, either at a different altitude or at a different time, within the scattering volume. The altitude range of a pulse is around $72 \mathrm{~km}$, so the power shown in Figs. 3 and 6 is at the location of the center of the $72 \mathrm{~km}$ range gate. The apparent smooth variation of the returns could be due to motions of the scatterers.
From Fig. 6 it can be seen that there is, on average, the same amount of up-shifted (blue) and down-shifted (red) power in the returns. Figure 7 shows the power in the two frequency ranges averaged over the altitude range (200 to $350 \mathrm{~km}$ ), plotted as a function of time. Figure 7 a shows the averaged power in the up-shifted shoulder, while Fig. $7 \mathrm{~b}$ shows the averaged power in the downshifted shoulder.

From Fig. 7 it can be seen that the overall power is approximately equal between the two shoulders. The exception to this is near time $6.25 \mathrm{~s}$, where there is a very enhanced upshifted shoulder, with no corresponding enhancement in the down-shifted shoulder. 


\section{Discussion}

\subsection{Implications of high time resolution for theories}

These observations are new in that these NEIALs can be followed with very high time resolution $(19 \mathrm{~ms})$, revealing their relation to dynamic auroral structures. The data presented here, in Figs. 1 and 2 versus Figs. 3 and 6, show clearly how the normal multi-second integration time of an ISR is much larger than the time-scale over which NEIALs and the associated auroral fine structures occur. Examining the raw data, as in Fig. 3, could allow for a more complete determination of the relevant timescale and the time evolution of NEIALs. A significant amount of the power is still contained within a few individual pulses, indicating that it is likely that the NEIAL returns could be even further structured on timescales less than $19 \mathrm{~ms}$. A yet higher time resolution measurement would likely still receive enough of the scattered power to examine more of the structure and development of the NEIALs. Typical raw data observations are limited in their use, however the returns from NEIALs are strong enough that it is possible to use the raw data to locate more accurately when they occur in relation to auroral forms. It is also possible to estimate the frequency offset of the enhanced returns, giving some indication of their generation and propagation. Full spectral analyses of these returns have not been made, but it can still be determined whether the enhanced returns are in the up-shifted shoulder, the down-shifted shoulder, or not significantly offset from the transmitted frequency.

These data show that during this NEIAL event, the amount of power in the up-shifted shoulder is approximately equal to the amount of power in the down-shifted shoulder on average. However with a time resolution of $19 \mathrm{~ms}$, it can be seen that this is not true for individual returns, as there can be significant departures in the amount of power in each ionacoustic shoulder. This is demonstrated in Fig. 7, where some of the strongest returns for this entire event occurred only in the up-shifted shoulder near 6.25 s. From Fig. 6 it can be seen that both the up- and down-shifted enhanced lines can occur at the same time (within $19 \mathrm{~ms}$ ), but that typically these enhanced returns occurred independently of one another.

Again, assuming enhanced backscatter from coherency in the plasma, enhancements in the upshifted shoulder correspond to scattering from ion-acoustic waves traveling toward the radar (or downward), while enhancements in the downshifted shoulder correspond to ion-acoustic waves traveling away from the radar (or upward). The data in Fig. 3, at $7.75 \mathrm{~s}$, extend over the altitude range from $325 \mathrm{~km}$ to $175 \mathrm{~km}$. The volume where these returns are coming from covers 2 range gates, therefore it is possible that some altitude propagation of the scattering region exists. There is no clear indication for upward or downward altitude propagation in this data, but these returns suggest that if there is any propagation in altitude, it must be very fast, greater than a few $\times 10^{6} \mathrm{~m} / \mathrm{s}$, which

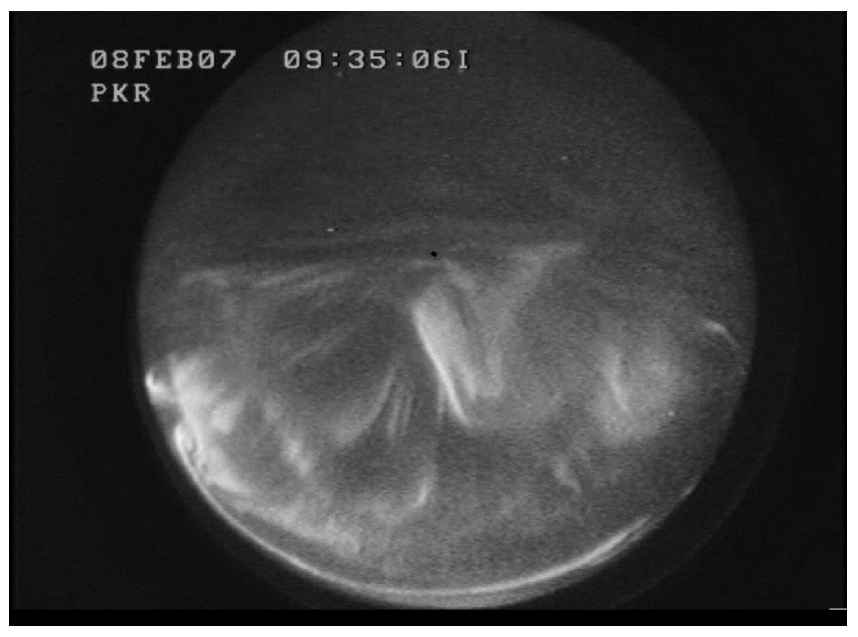

Fig. 5. All-sky camera image taken from 09:35:06 UT, showing the large-scale auroral context of this NEIAL event. The location of the PFISR beam at $100 \mathrm{~km}$ altitude is shown as the small black box near the center of the image. This shows the tall auroral rays that were present during this event. (North is down and east is to the right).

is approximately $V_{A}$, the Alfvén speed in this region, based on the derived parameters from the radar data. This is greater than the Langmuir wave phase velocity in this region, which is around a few $\times 10^{5} \mathrm{~m} / \mathrm{s}$, given a k-vector of $3.0 \mathrm{~m}^{-1}$. Since this is an order of magnitude less than the estimated lower bound, and Langmuir waves are non-propagating waves, it is unlikely that they are involved in the propagation of these returns. This technique is likely to yield better altitude propagation estimates for NEIAL events with stronger, more structured returns. The structure of the returns (apparently localized in altitude) suggest that the scattering does not occur continuously, but rather intermittently during very short times within the transmitted pulse.

Another plausible generation mechanism, relating to altitude propagation on the order of the Alfvén speed, is that the returns could be coming from a secondary response to the Alfvén waves, either incoming (downward propagating) or reflected (upward propagating). The ion-acoustic waves could be generated by an interaction of the Alfvén wave with the plasma, producing both upward and downward propagating ion acoustic waves. Recent theoretical and observational work by Chaston et al. $(2007,2008)$ have showed that Alfvén wave power can cascade down from larger to smaller scales in turbulent Alfvénic aurora. If enough Alfvén wave power were to cascade down to the radar half wavelength scale $(0.33 \mathrm{~m})$, it seems possible that ion acoustic waves could be driven unstable, however no explicit mechanism has yet been established showing that Alfvén waves impinging on the ionosphere cause ion-acoustic waves to be generated.

Another interpretation of this altitude propagation signal comes from the motion of the k-vector matching condition 


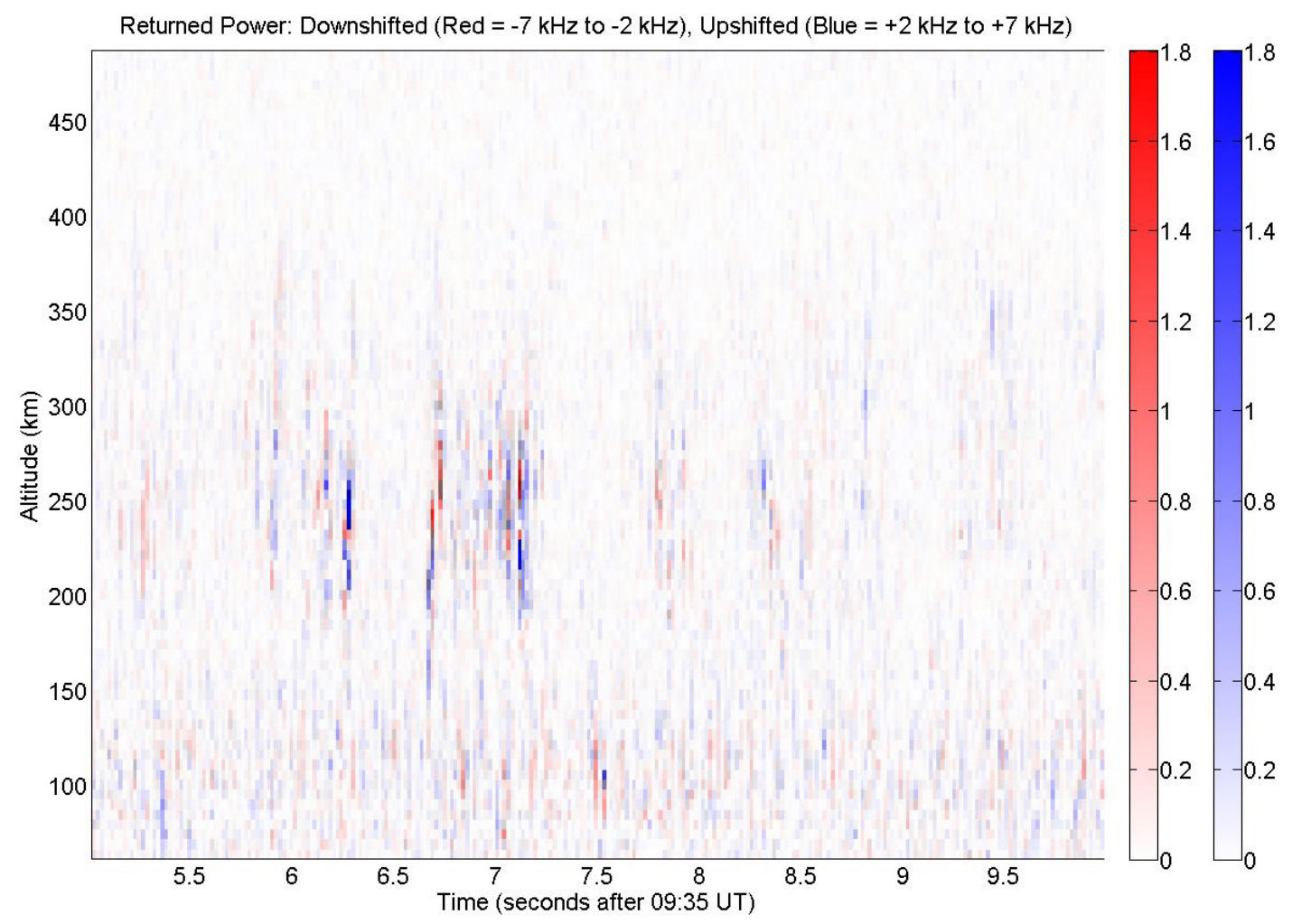

Fig. 6. Summary of the returned power in the NEIALs from the raw data as a function of time and altitude, broken down into two frequency ranges, enhanced up-shifted shoulders ( 2 to $7 \mathrm{kHz}$, shown in blue) and enhanced down-shifted shoulders ( $-7 \mathrm{ko}-2 \mathrm{kHz}$ shown in red). Again, these raw data are not corrected for the $\frac{1}{r^{2}}$ decrease in power with distance.

along the magnetic field. The strong backscatter associated with NEIALs is presumed to come from a k-vector matching (Bragg) condition with enhanced ion acoustic waves. The NEIALs only come from the region where the Bragg condition is met. Therefore it is possible that it is only the matching condition that is moving, rather than the waves themselves (N. Ivchenko, personal communication).

Whether or not the enhancements on both ion-acoustic shoulders are simultaneous or not has implications for theories explaining NEIAL generation. The electron-ion twostream (current-driven) instability can only enhance one ionacoustic shoulder at a time, depending on the direction of the current. Upward moving electrons (downward current) would enhance the downshifted shoulder, and downward moving electrons (upward current) would enhance the upshifted shoulder (Rietveld et al., 1991). The ion-ion twostream instability and the Langmuir decay theory can produce both simultaneously and individually enhanced upand down-shifted ion-acoustic shoulders (Grydeland et al., 2004). The finite temporal and spatial resolution of radar data have made it difficult to test this, and previous studies of NEIALs have observed both examples of the two shoulders enhanced independently of one another, and the two enhanced simultaneously, down to the time resolutions used (Foster et al., 1988; Collis et al., 1991; Rietveld et al., 1991; Sedgemore-Schulthess et al., 1999; Ogawa et al., 2000; Grydeland et al., 2003, 2004; Strømme et al., 2005). The very high resolution radar data used here indicate that the enhanced upshifted and downshifted shoulders occur predominantly apart from one another on these very short timescales. The current-driven instability, therefore, is not a viable mechanism to explain these data, as the driving fields are unlikely to reverse on such short time scales.

\subsection{Relation to camera data}

One way to gain more information about the processes that are occurring inside the radar beam is to complement the observations with conjugate high-resolution imaging of the aurora. This gives an indication of the upward-current regions (UCRs) within the radar beam on a $33 \mathrm{~ms}$ time-scale, and it is also argued that some downward current regions (DCRs) can be identified in the camera data as well, based on morphology arguments (Michell et al., 2008b). In a companion study, Michell et al. (2008a) found NEIALs to occur at the poleward edge of a large scale $(\geq 10 \mathrm{~km})$ quasi-stable arc structure. Based on known auroral morphology from in situ 
(a) Upshifted Power Altitude Range: $200 \mathrm{~km}$ to $350 \mathrm{~km}$

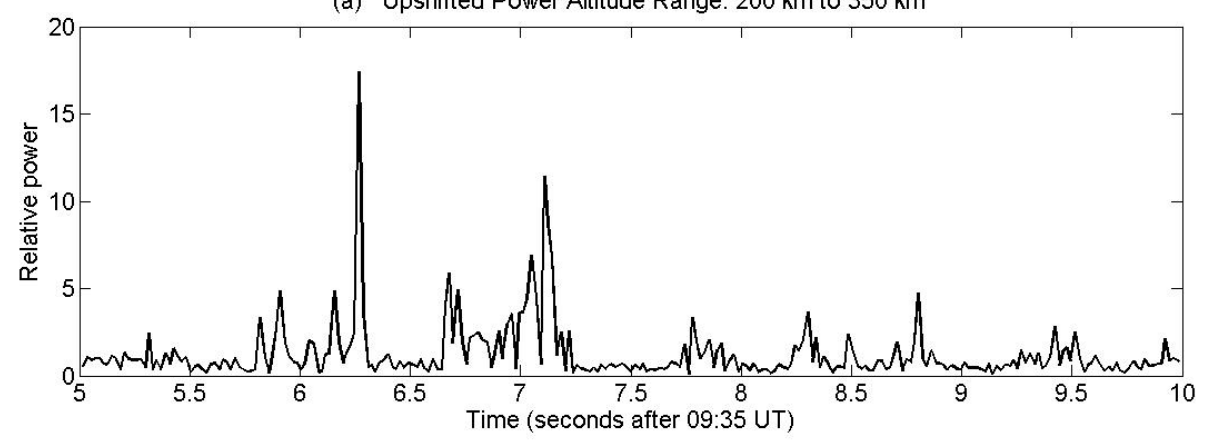

(b) Downshifted Power Altitude Range: $200 \mathrm{~km}$ to $350 \mathrm{~km}$

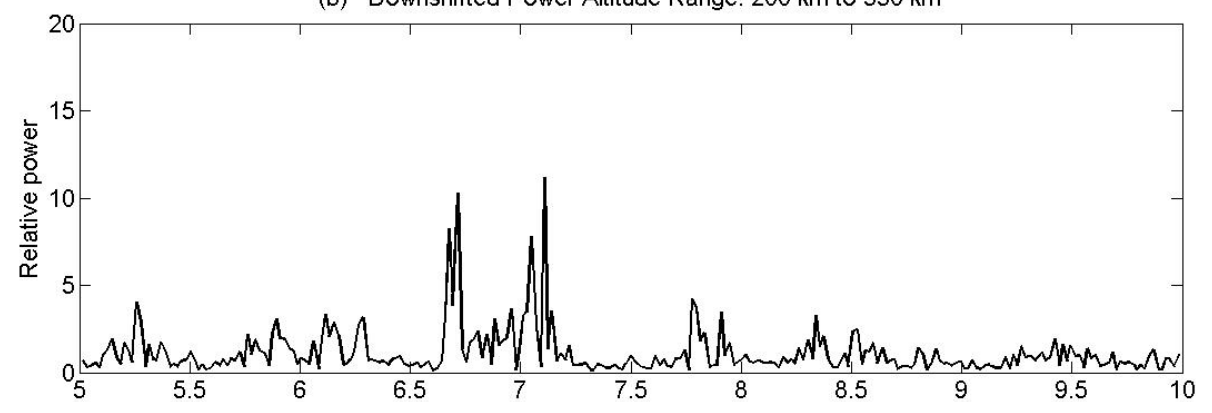

Fig. 7. The relative power, in arbitrary units, from Fig. 6, summed over altitude, (200 to $350 \mathrm{~km})$, shown as a function of time for the two frequency ranges. Panel (a) is the up-shifted power $(2$ to $7 \mathrm{kHz})$ and $(\mathbf{b})$ is the downshifted power $(-7 \mathrm{to}-2 \mathrm{kHz})$.

studies, the poleward edge of such auroral arcs are known to contain many of the same characteristics as DCRs, such as large fluxes of low energy electrons, Alfvénically accelerated electrons, and broad band extremely low frequency (BBELF) wave activity. Therefore a connection between NEIALs and DCRs may likely be a connection with one or more of these common characteristics.

It is known from in situ measurements that significant wave activity $(0.1 \mathrm{~Hz}$ to $10 \mathrm{kHz}$ range) occurs within the DCRs (Kintner et al., 1996; Bonnell et al., 1996; Wahlund et al., 1998; Knudsen and Wahlund, 1998; Lynch et al., 1996, 2002, 2007). Note that the NEIALs only occurred on one side (the leading edge) of the fast moving arc that passed through the radar beam in this event. There appears to be something different about this side of the dynamic arc, and it is certainly possibly that the leading edge (the equatorward side in this case) is the region with more turbulent Alfvén wave activity. Figure 3 only shows up to $09: 35: 10$ UT to best present the fine structure of the strong NEIAL returns. The raw data from the time period both before and after that shown in Fig. 3 showed no signs of any enhanced returns.

The morphology of the current structures, measured in situ, inside regions of Alfvénic activity and polar cap boundary auroral features, typically contain both upward and downward currents very near each other. Chaston et al. (2003) report measurements of Alfvén waves from the FAST satellite in the cusp and in the polar cap boundary regions.
They found that, in both the cusp and polar cap boundary, Alfvén waves capable of producing small-scale $(\leq 1 \mathrm{~km})$ visible auroral structures were associated with large fluxes of low energy ( $100 \mathrm{eV}$ to $1 \mathrm{keV}$ ) electrons. The current densities associated with these Alfvén waves are found to be very large (10 to $100 \mu \mathrm{A} / \mathrm{m}^{2}$ ). Their observations are summarized in Fig. 6 of Chaston et al. (2003) and the typical scale sizes of these structures are on the order of $900 \mathrm{~m}$. This suggests that small-scale dynamic auroral arcs seen in camera data, such as the one reported here, could be associated with Alfvénic acceleration of electrons.

\section{Conclusions}

Continued observations of NEIALs with high time resolution radar measurements in conjunction with high-resolution images of the aurora are needed in order to continue to investigate the auroral plasma physics involved in their generation. The exact nature of the NEIAL scattering processes and generation mechanisms are not known. Therefore to gain insight into the physics involved with their generation, it is assumed that NEIALs result from coherency in the plasma, on the Bragg scattering scale. The data presented here indicate that the time resolution of these measurements $(19 \mathrm{~ms})$ is approaching the time-scales involved with NEIAL generation, but that higher resolution may still be needed to more fully understand these processes. These 
high-resolution measurements can be used to follow the development of the enhancements as a function of altitude and time. This will give information regarding their propagation in altitude, and the time development of their spectral features, which offers valuable information regarding their formation. The data also show that the up- and down-shifted enhancements occur predominately independent of one another. These NEIALs occurred on the boundary of a dynamic bright auroral structure and may be associated with the turbulent cascading of Alfvén wave power.

Acknowledgements. This work was supported under NASA grant \# NAG5-5415 and the NASA space grant, \# NNG05GG76H. The authors would like to thank G. T. Marklund, T. Karlsson, N. Ivchenko, J. Semeter, W. Lotko, and R. Millan for their valuable input.

Topical Editor M. Pinnock thanks two anonymous referees for their help in evaluating this paper.

\section{References}

Blixt, E. M., Grydeland, T., Ivchenko, N., Hagfors, T., La Hoz, C., Lanchester, B. S., Løvhaug, U. P., and Trondsen, T. S.: Dynamic rayed aurora and enhanced ion-acoustic radar echoes, Ann. Geophys., 23, 3-11, 2005, http://www.ann-geophys.net/23/3/2005/.

Bonnell, J., Kintner, P., Wahlund, J. E., Lynch, K., and Arnoldy, R.: Interferometric determination of broadband ELF wave phase velocity within a region of transverse auroral ion acceleration, Geophys. Res. Lett., 23, 3297-3300, 1996.

Chaston, C. C., Peticolas, L. M., Bonnell, J. W., Carlson, C. W., Ergun, R. E., McFadden, J. P., and Strangeway, R. J.: Width and brightness of auroral arcs driven by inertial Alfven waves, J. Geophys. Res. (Space Physics), 108, 1091, doi:10.1029/ 2001JA007537, 2003.

Chaston, C. C., Hull, A. J., Bonnell, J. W., Carlson, C. W., Ergun, R. E., Strangeway, R. J., and McFadden, J. P.: Large parallel electric fields, currents, and density cavities in dispersive Alfvén waves above the aurora, J. Geophys. Res., 112(A11), A05215, doi:10.1029/2006JA012007, 2007.

Chaston, C. C., Salem, C., Bonnell, J. W., Carlson, C. W., Ergun, R. E., Strangeway, R. J., and McFadden, J. P.: The Turbulent Alfvénic Aurora, Phys. Rev. Lett., 100, 17, doi:10.1103/PhysRevLett.100.175003, 2008.

Collis, P. N., Haggstrom, I., Kaila, K., and Rietveld, M. T.: EISCAT radar observations of enhanced incoherent scatter spectra and their relation to red aurora and field-aligned currents, Geophys. Res. Lett., 18, 1031-1034, 1991.

Forme, F. R. E.: A new interpretation of the origin of enhanced ion acoustic fluctuations in the upper ionosphere, Geophys. Res. Lett., 20, 2347-2350, 1993.

Forme, F. R. E.: Parametric decay of beam-driven Langmuir wave and enhanced ion-acoustic fluctuations in the ionosphere: a weak turbulence approach, Ann. Geophys., 17, 1172-1181, 1999, http://www.ann-geophys.net/17/1172/1999/.

Foster, J. C., del Pozo, C., Groves, K., and Saint Maurice, J.-P.: Radar observations of the onset of current driven instabilities in the topside ionosphere, Geophys. Res. Lett., 15, 160-163, 1988.
Grydeland, T., La Hoz, C., Hagfors, T., Blixt, E. M., Saito, S., Strømme, A., and Brekke, A.: Interferometric observations of filamentary structures associated with plasma instability in the auroral ionosphere, Geophys. Res. Lett., 30, 1338, doi:10.1029/ 2002GL016362, 2003.

Grydeland, T., Blixt, E. M., Løvhaug, U. P., Hagfors, T., La Hoz, C., and Trondsen, T. S.: Interferometric radar observations of filamented structures due to plasma instabilities and their relation to dynamic auroral rays, Ann. Geophys., 22, 1115-1132, 2004, http://www.ann-geophys.net/22/1115/2004/.

Grydeland, T., Gustavsson, B., Baddeley, L., Lunde, J., and Blixt, E. M.: Conditional integration of Incoherent Scattering in relation to flickering aurora, J. Geophys. Res., 113, 8305, doi: 10.1029/2008JA013039, 2008.

Kintner, P. M., Bonnell, J., Arnoldy, R., Lynch, K., Pollock, C., and Moore, T.: SCIFER-Transverse ion acceleration and plasma waves, Geophys. Res. Lett., 23, 1873-1876, 1996.

Knudsen, D. J. and Wahlund, J.-E.: Core ion flux bursts within solitary kinetic Alfvén waves, J. Geophys. Res., 103, 4157-4170, 1998.

Lunde, J., Gustavsson, B., Løvhaug, U. P., Lorentzen, D. A., and Ogawa, Y.: Particle precipitations during NEIAL events: simultaneous ground based observations at Svalbard, Ann. Geophys., 25, 1323-1336, 2007, http://www.ann-geophys.net/25/1323/2007/.

Lynch, K. A., Arnoldy, R. L., Kintner, P. M., and Bonnell, J.: The AMICIST auroral sounding rocket: A comparison of transverse ion acceleration mechanisms, Geophys. Res. Lett., 23, 32933296, 1996.

Lynch, K. A., Bonnell, J. W., Carlson, C. W., and Peria, W. J.: Return current region aurora: $E_{\text {parallel }}, j_{z}$, particle energization, and broadband ELF wave activity, J. Geophys. Res., 107, 1115, doi: 10.1029/2001JA900134, 2002.

Lynch, K. A., Semeter, J. L., Zettergren, M., Kintner, P., Arnoldy, R., Klatt, E., LaBelle, J., Michell, R. G., MacDonald, E. A., and Samara, M.: Auroral ion outflow: low altitude energization, Ann. Geophys., 25, 1967-1977, 2007, http://www.ann-geophys.net/25/1967/2007/.

Markkanen, J., Lehtinen, M., and Landgraf, M.: Real-time space debris monitoring with EISCAT, Adv. Space Res., 35, $1197-$ 1209, doi:10.1016/j.asr.2005.03.038, 2005.

Michell, R. G., Lynch, K. A., Heinselman, C. J., and StenbaekNielsen, H. C.: PFISR nightside observations of naturally enhanced ion acoustic lines, and their relation to boundary auroral features, Ann. Geophys., 26, 3623-3639, 2008a, http://www.ann-geophys.net/26/3623/2008/.

Michell, R. G., Lynch, K. A., and Stenbaek-Nielsen, H. C.: Groundbased observational signature of a downward current channel in an active auroral arc, Geophys. Res. Lett., 35, 8101, doi:10.1029/ 2008GL033596, 2008b.

Ogawa, Y., Fujii, R., Buchert, S. C., Nozawa, S., Watanabe, S., and van Eyken, A. P.: Simultaneous EISCAT Svalbard and VHF radar observations of ion upflows at different aspect angles, Geophys. Res. Lett., 27, 81-84, 2000.

Ogawa, Y., Buchert, S. C., Fujii, R., Nozawa, S., and Forme, F.: Naturally enhanced ion-acoustic lines at high altitudes, Ann. Geophys., 24, 3351-3364, 2006, http://www.ann-geophys.net/24/3351/2006/.

Rietveld, M. T., Collis, P. N., and St.-Maurice, J.-P.: Naturally en- 
hanced ion acoustic waves in the auroral ionosphere observed with the EISCAT 933-MHz radar, J. Geophys. Res., 96, 1929119305, 1991.

Rietveld, M. T., Collis, P. N., Vaneyken, A. P., and Løvhaug, U. P.: Coherent echoes during EISCAT UHF Common Programmes, J. Atmos. Terr. Phys., 58, 161-174, 1996.

Sedgemore-Schulthess, F. and St. Maurice, J.-P.: Naturally Enhanced Ion-Acoustic Spectra And Their Interpretation, Surv. Geophys., 22, 55-92, 2001.

Sedgemore-Schulthess, K. J. F., Lockwood, M., Trondsen, T. S., Lanchester, B. S., Rees, M. H., Lorentzen, D. A., and Moen, J.: Coherent EISCAT Svalbard Radar spectra from the dayside cusp/cleft and their implications for transient field-aligned currents, J. Geophys. Res., 104, 24613-24624, 1999.
Strømme, A., Belyey, V., Grydeland, T., La Hoz, C., Løvhaug, U. P., and Isham, B.: Evidence of naturally occurring wave-wave interactions in the polar ionosphere and its relation to naturally enhanced ion acoustic lines, Geophys. Res. Lett., 32, 5103, doi: 10.1029/2004GL020239, 2005.

Wahlund, J.-E., Forme, F. R. E., Opgenoorth, H. J., Persson, M. A. L., Mishin, E. V., and Volokitin, A. S.: Scattering of electromagnetic waves from a plasma - Enhanced ion acoustic fluctuations due to ion-ion two-stream instabilities, Geophys. Res. Lett., 19, 1919-1922, 1992.

Wahlund, J.-E., Eriksson, A. I., Holback, B., Boehm, M. H., Bonnell, J., Kintner, P. M., Seyler, C. E., Clemmons, J. H., Eliasson, L., Knudsen, D. J., Norqvist, P., and Zanetti, L. J.: Broadband ELF plasma emission during auroral energization 1. Slow ion acoustic waves, J. Geophys. Res., 103, 4343-4376, 1998. 